Welcome to our newest issue of Hypothesis! We hope you enjoy reading the content in this issue and learning about the changes we have made in the past year.

\title{
ISSUE PREVIEW
}

Invited Commentaries (Wilson, Carroll, Adamczyk)

In Spring 2021, Alexandria Q. Wilson wrote a review on the inaugural "One Database at a Time" webinar. This series of webinars is co-hosted by the Technology in Education Caucus and the Systematic Reviews Caucus. Feel free to join either caucus and view all the webinars in this series on the Technology in Education Caucus website.

As a response to increased levels of anti-Asian bias, hate, and violence, Immediate Past-Chair Alexander J. Carroll released a statement of solidarity with Asian, AsianAmerican, and Pacific Islander community members in March 2021. The statement links to the Asian Pacific American Librarians Association (APALA)'s statement on these issues and provides important training resources for Bystander Intervention.

Finally, Abby Admaczyk, current Chair of the Research Caucus, compiled guidance on how to write structured abstract research proposals for conferences. This information is useful in particular for new authors, who are writing structured abstracts for the first time.

\section{Research Article (Morgan-Daniel et al.)}

The University of Gainesville's Health Science Center Libraries (HSCL) conducted a diversity, equity, and inclusion (DEI) needs assessment to learn more about patrons' perception of the current libraries' climate as well as identify strengths, gaps, and areas to improve upon. HSCL gained helpful information from this work and identified a number of next steps to improve their engagement with DEI across their libraries. The process described in this article also provides an excellent template for other organizations looking to conduct this type of assessment.

\section{Research Caucus Awards}

As is tradition, this issue includes the list of awards given out by the Research Caucus for MLA 2021 conference research papers and posters. Congratulations to those who received an award for their excellent research! We encourage all past and current Research Caucus Award recipients to consider submitting articles to Hypothesis.

\section{HYPOTHESIS ARCHIVES}

All past issues (67 in total!) of Hypothesis are now available in the Archives section of the website. Below are four facts Margaret discovered about Hypothesis and the Research Caucus while completing this work: 
1. Pre-2010, this was a newsletter for the Research Section and it was published 3 times a year. It contained Annual Meeting updates, a roster of members, and a list of research topics.

2. In 2010, the first MLA Annual Meeting Research Awards criteria were established and the first award recipients were featured in Hypothesis.

3. The conversion from newsletter to journal started in 2013 and the first official journal issue was published in 2014.

4. Though the editorial team has turned over several times, the quality of publications remains consistent.

We encourage you to browse our robust Archive to learn more about the evolution of Hypothesis from a newsletter to an open access journal.

\section{EDITORIAL BOARD UPDATES}

New Members

We welcome Matthew (Matt) Cross, who graduates in December 2021 from Texas Woman's University, as a new Peer-Reviewer Co-Lead. Matt has served as a peer reviewer for a number of issues and we know his expertise will assist us in improving how Hypothesis handles peer review.

In January 2021, Alexandria (Alex) Quesenberry Wilson joined the Social Media Team for Hypothesis. With her experience working on the Library and Information Science journal as a graduate student, Alex brings a wealth of knowledge and experience for how we can continue to grow the journal. Additionally, Alex is an up-and-coming researcher, who was a recipient of an MLA 2021 Research Caucus Award.

Wishing them the best!

We would like to thank Kimberly (Kim) Powell for onboarding Matt and assisting us in developing a structure for peer reviewing and workflow in OJS. We thank her for continuing to serve as a peer reviewer for Hypothesis.

Additionally, in August 2020, Amy Reyes joined the inaugural Social Media Team for Hypothesis. Amy worked closely with Danielle Aloia to create a distribution list, which the Social Media Team will use to solicit new submissions and to publicize new issues. We thank you, Amy, for your contributions and we wish you well.

Last (but not least!), from 2017-2021, Erin D. Foster has served as Editor of Hypothesis. Erin was joined by Carol Perryman in 2018 as Co-Editor and in 2020, Margaret Hoogland was recruited to serve as Co-Editor while Erin transitioned out of her role. Erin has worked tirelessly to initially create an online submission for Hypothesis in MLAnet and then to migrate the journal from MLAnet onto the Open Journal System 


\section{EDITORIAL}

platform. If an issue cropped up at any point related to the website, workflow, etc, Erin jumped in and fixed it. Last Fall, Erin moved back to California and became the Service Lead for the University of California Berkeley Research Data Management Program.

We thank Erin for her time and dedication to Hypothesis. Although we will miss her, we wish her all the best and we are thankful she has agreed to continue serving as a peer reviewer for Hypothesis.

If you have suggestions for how we can improve the journal -- or if you have questions for us, we encourage you to contact the $\underline{\text { Co-Editors. }}$

Your Hypothesis Co-Editors,

Erin D. Foster

Margaret A. Hoogland

Carol L. Perryman 